\title{
PREVALENCE OF PSYCHOSEXUAL DYSFUNCTIONS AMONG HEMODIALYSIS MALE PATIENTS ${ }^{1}$ Ahmed Hashem El-Sayed El-Monshed, ${ }^{2}$ Nelly Ahmed Mahgoub, ${ }^{3}$ Hassan Abol-Enein Abdel-Baky, ${ }^{4}$ Samah Mohammed Taha \\ ${ }^{1,}{ }^{4}$ Psychiatric and Mental Health Nursing Department, Faculty of Nursing-Mansoura University \\ ${ }^{2}$ Psychiatric and Mental Health Nursing, Faculty of Nursing-Cairo University \\ ${ }^{3}$ Faculty of Medicine - Urology \& Nephrology Center - Mansoura University E-mail: ahmed elmonshed@mans.edu.eg drahmed014@yahoo.com
}

\begin{abstract}
: liaison nursing.

\section{Introduction:}

Chronic kidney disease (CKD) is a worldwide public-health problem. According to the World Health Organization, diseases of the kidney and urinary tract contribute to global burden with approximately 850,000 deaths every year and more than 115 million disabilityadjusted life years ${ }^{[1]}$. Currently in Egypt, hemodialysis represents the main mode of treatment of CKD patients ${ }^{[2]}$. The prevalence of dialysis patients in Egypt has increased from 10 per million population (pmp) in 1974 to $225 \mathrm{pmp}$ in 1996, and then from $403 \mathrm{pmp}$ in 2003 to 483 in $2004^{[1]}$.
\end{abstract}

Background: Chronic kidney disease (CKD) is a worldwide public-health problem in which most of the physical functions of the body are affected including sexual function. Apart from physical impacts due to renal failure, there are a number of psychological impacts that may also contribute to changes in sexual functioning. Therefore, the aim of this study is to assess the prevalence of psychosexual dysfunctions experienced by hemodialysis male patients. Methods: A descriptive cross-sectional research design was conducted in the hemodialysis units at Mansoura Urology and Nephrology Center. The data were collected from 100 hemodialysis male patients who corresponded to the inclusion criteria. Arizona Sexual Experience Scale (ASEX) and Psychosexual Dysfunction Questionnaires were used to achieve the purpose of the study. Results: The results indicate that $(94 \%)$ of the study sample complain of psychosexual dysfunctions. The most prevalent psychosexual dysfunctions are psychosexual discomfort, fatigue, low self-esteem during sex, difficulty in reaching orgasm, difficulty in maintenance erection and low sexual desire while suicidal ideation was the lowest prevalent psychosexual dysfunctions. Conclusion: The vast majority of the study sample has psychosexual dysfunctions. Application of psychiatric liaison nursing program in hemodialysis units is recommended.

Keywords:Chronic Kidney Disease; Hemodialysis; Psychosexual dysfunctions; Psychiatric

Abbreviations: CKD (Chronic Kidney Disease); ED (Erectile Dysfunctions)

When patients develop kidney disease, every organ of the body is affected. One of the main dysfunctions is the sexual function Sexual dysfunction is very common in patients with kidney disease $^{[3,4]}$.

Prevalence estimates of sexual dysfunction range from $9 \%$ in pre-dialysis to $70 \%$ in dialysis patients of either sex ${ }^{[5]}$.

Notably, sexuality is a basic human right and a fundamental part of a full and healthy life ${ }^{[6]}$. Accordingly, sexuality is defined as a phenomenon in which biological and psychological factors interact, so both a person's physical condition and his or her psychological 
well-being represent interdependent cornerstones of sexual health ${ }^{[7]}$. In other words, psychosexual dysfunction is a sexual dysfunction that is due to psychological causes rather than physical problems, medical illnesses, or the side effects of medication. Some of the psychological conditions include: depression, anxiety (feelings of nervousness, fear), traumatic sexual experience, guilty feelings of stress or anxiety, uncertainty about sexual orientation worry or fear about how you are able to perform sexually negative body image $^{[8]}$.

Regarding the hemodialysis patients, researchers addressed the sexual dysfunctions namely alterations related to drive, subjective arousal, penile erection/vaginal lubrication, ability to reach orgasm and satisfaction with $\operatorname{orgasm}^{[9]}$. In this respect, impotence or erectile dysfunction (ED) is reported to be the commonest sexual dysfunction complaint amongst men with renal failure $^{[10]}$. In Egypt $82.5 \%$ of hemodialysis patients have $E D^{[11]}$. Several studies addressed psychosocial causes that have been purported to contribute to sexual dysfunction in patients with CKD include depression, anxiety, poor self-esteem, social withdrawal, marital discord, body image issues, fear of disability and death, loss of employment, and financial difficulties $^{[12.13]}$. At times the discussion of causation falls into a chicken or egg debate as the dominance of physiological and psychological factors are discussed ${ }^{[10]}$.

Nurses can use nursing process in determining and addressing the psychosexual problems of individuals. Nursing process occurs from four stages should be applied on psychosexual dysfunctions. Each stage is different, but it also completes each other. These stages are assessment, planning, implementation and evaluation. In order to give effective and qualified psychosexual care of people, nurses working in accordance with nursing process play a key role in achieving success $^{[14]}$.

In other words, liaison nurse can apply psycho-education, to convey to the patient the relevance of psychological factors; problem-solving and other supportive strategies such as motivational interviewing; specialist psychological therapies such as cognitive behavior therapy or interpersonal therapy; consideration of social, family and practical problems; and the possible use of medication ${ }^{[15,16]}$. Additionally, training of hospital staff by liaison psychiatric nurses can improve the ability of hospital staff to identify mental health conditions and the quality of care provided by acute hospital staff $^{[16]}$.

\section{Significance of the study:}

In Egypt, the estimated total prevalence of patients on dialysis is 264 per million ${ }^{[17]}$. In 2011, the number of cases of both sex on hemodialysis in Mansoura Urology and Nephrology Center was 590 cases. Because of this high prevalence, it is important to assess the prevalence of psychosexual dysfunctions as a major stressor in hemodialysis patient's life.

Aim of the study:

The study was conducted to assess the prevalence of psychosexual dysfunctions experienced by hemodialysis male patients.

\section{Materials and Method \\ Materials \\ Design:}

The study was carried out using a descriptive cross-sectional research design. Setting:

The study was conducted at the hemodialysis units of Urology and Nephrology Center at Mansoura University.

\section{Sample:}

A convenient accidental sample of 100 hemodialysis male patients who 
PREVALENCE OF PSYCHOSEXUAL DYSFUNCTIONS AMONG etc...

corresponded the following inclusion criteria:

1. Male patients on hemodialysis wasn't the first session for the patient.

2. Both acute and chronic kidney disease.

3. Married before starting hemodialysis and still married after dialysis.

4. Aged 20-60 years.

5. Pre-morbid sexually active adult males.

6. Willingly to voluntarily participate in the study.

7. Under treatment at the time of data collection.

Tools for data collection:

In order to collect the necessary data

for this study, three tools have been used:

1. Socio-demographic and Clinical Data Structured Interview Schedule: is designed by the researcher to assess all related demographic and clinical data of the sample including: age, residence, duration of marriage, level of education, duration of hemodialysis treatment and medical history.

2. Arizona Sexual Experience Scale (ASEX): this is a 4-point self rating scale developed to assess the premorbid healthy sexual functioning with regard to the following 5 domains: Sexual Drive, Arousal, Penile Erection, Reaching Orgasm, and Satisfaction with Orgasm $^{[18]}$. A total score $>12$ is indicative of clinically significant sexual dysfunction. This tool was used in this study to assess the sexual functions of the studied patients before starting hemodialysis. Any patient has significant sexual dysfunction, has been excluded from the study.

3. Psychosexual

Dysfunction Questionnaire (Male-Version): this questionnaire was originally developed under the name of the Sexual Dysfunction Questionnaire (SDQ) ${ }^{[19]}$. In the current study, this questionnaire was modified by the researcher to assess the psychosexual functioning of the male patients after starting hemodialysis under a new name is a Psychosexual Dysfunction Questionnaire (Male-Version). The questionnaire consists of 19 questions. Eight questions (number; $3,4,5,6,7,13,14$, and 15) concerning with physical symptoms of psychosexual dysfunctions such as fatigue, low sexual desire, difficulty in reaching orgasm, difficulty in beginning erection, and difficulty in keeping erection. On the other hand eleven questions (number; 1, 2, 8, 9, 10, 11, $12,16,17,18$, and 19) concerning with the psychological symptoms of psychosexual dysfunctions such as sexual dissatisfaction, low self-esteem during sex, loss of hope, anxiety, and fear of sex, depressed mood, and suicidal ideation. Men with score $\geq 45$ (the optimal cut-off score) have the risk to have psychosexual dysfunctions than those with scores $\leq 44$. Reliability of the tool was held on 10 hemodialysis male patients. Test-retest-reliability coefficient was held on the same patients by the same investigator within 14 days interval in the same setting. Its value for 19 items was (0.77).

Method:

\begin{tabular}{|c|c|c|}
\hline \multicolumn{3}{|c|}{ Age in years } \\
\hline \multicolumn{3}{|c|}{ Number } \\
\hline $20-(<30)$ & 5 & 5 \\
\hline $30-(<40)$ & 30 & 30 \\
\hline $40-(<50)$ & 37 & 37 \\
\hline $50-60$ & 28 & 28 \\
\hline \multicolumn{3}{|c|}{ Residence } \\
\hline Rural & 55 & 55 \\
\hline Urban & 45 & 45 \\
\hline \multicolumn{2}{|c|}{ Marriage Duration in years } \\
\hline$<5$ years & 14 & 14 \\
\hline $5-(<15)$ & 40 & 40 \\
\hline $15-25$ & 29 & 29 \\
\hline$>25$ & 17 & 17 \\
\hline
\end{tabular}


Official permission was obtained from the head of the hemodialysis department and from the head nurse at the three study settings to conduct the study. Verbal and informed consent obtained from the respondents before their inclusion in the study. Nature and aim of the study were explained to each member of the participants. Each patient was individually interviewed to collect the necessary data in privacy. Ethical consideration was obtained from the Research Ethics Committee of the Faculty of Nursing Mansoura University.

\section{Statistical analysis:}

Data were analyzed with SPSS version 16 . The normality of data was first tested with one-sample KolmogorovSmirnov test. Qualitative data were described using numbers and percent. Continuous variables were presented as mean \pm SD (standard deviation) for parametric data and Median for nonparametric data.

\section{Results:}

In relation to the socio-demographic data of the study sample, results demonstrate that more than two thirds of the study sample $(67 \%)$ age 30 to 49 years old, As regard the residence, more than half of the study sample $(55 \%)$ are living in rural areas while (45\%) are living in urban. In relation to the marriage duration, two fifth of the study sample $(40 \%)$ are married for 5 to 15 years. Concerning the educational level, more than half of the study sample (59\%) are middle educated. (Table, 1).

Table (1):

Socio-demographic characteristics of the studied sample $(\mathrm{n}=100)$ :
Table (1) (Cont'd): Socio- demographic characteristics of the studied sample $(\mathrm{n}=100)$ :

\begin{tabular}{|c|c|c|}
\hline Item & Number & \% \\
\hline \multicolumn{2}{|c|}{ Educational Level } \\
\hline $\begin{array}{c}\text { Illiterate } \\
\text { Non-educated } \\
\text { (Read and } \\
\text { write) }\end{array}$ & 9 & 9 \\
\hline $\begin{array}{c}\text { Middle } \\
\text { education }\end{array}$ & 59 & 59 \\
\hline High education & 20 & 20 \\
\hline
\end{tabular}

Regarding the clinical data, more than half of the study sample (62\%) undergo hemodialysis for more than 3 years. As regard the hemodialysis co-morbidity, more than half of the study sample $(58 \%)$ suffer from medical disease while $(42 \%)$ are medically free (Table, 2).

Table (2): Clinical data of the studied sample $(n=100)$ :

\begin{tabular}{|c|c|c|}
\hline Item & Number & $\%$ \\
\hline \multicolumn{3}{|c|}{ Hemodialysis duration in years } \\
\hline$<$ Year & 16 & 16 \\
\hline $1-(<3)$ years & 22 & 22 \\
\hline $3-6$ years & 33 & 33 \\
\hline$>6$ years & 29 & 29 \\
\hline \multicolumn{3}{|c|}{ Hemodialysis Co-morbidity } \\
\hline Free & 42 & 42 \\
\hline $\begin{array}{c}\text { Endocrinal } \\
\text { diseases }\end{array}$ & 15 & 15 \\
\hline $\begin{array}{c}\text { Circulatory } \\
\text { (Hypertension } \\
\text { and cardiac } \\
\text { diseases) }\end{array}$ & 12 & 12 \\
\hline $\begin{array}{l}\text { Hepatitis (B or } \\
\text { C) }\end{array}$ & 25 & 25 \\
\hline $\begin{array}{c}\text { Others } \\
\text { (Osteoporosis, } \\
\text { rheumatoid } \\
\text { arthritis) }\end{array}$ & 6 & 6 \\
\hline
\end{tabular}

dysfunction score, the findings reveal that the vast majority of the study sample 
(94\%) complains of psychosexual dysfunctions while only $6 \%$ expressed good psychosexual functions (Table, 3 ).

Table (3) : Frequency and percentage distribution of the studied sample with regard to Psychosexual Dysfunctions $(n=100)$ :

\begin{tabular}{|c|c|c|c|}
\hline \multicolumn{2}{|c|}{$\begin{array}{c}\text { Psychosexual } \\
\text { Dysfunctions }\end{array}$} & \multicolumn{2}{c|}{$\begin{array}{c}\text { Good Psychosexual } \\
\text { Functioning }\end{array}$} \\
\hline Number & $\%$ & Number & $\%$ \\
\hline 94 & 94 & 6 & 6 \\
\hline
\end{tabular}

On the part of physical symptoms, fatigue, difficulty in reaching orgasm, difficulty in keeping erection, low sexual desire, impaired sexual arousal and difficulty in beginning erection are the most common physical symptoms expressed by the studied sample with mean of (3.76), (3.34), (3.32), (3.31), (3.29) and (3.14) out of a possible score of (4) respectively (Table, 4$)$.

Table(4):Physical symptoms of Psychosexual Dysfunctions of the studied sample $(n=100)$ :

\begin{tabular}{|c|c|c|c|}
\hline $\begin{array}{c}\text { Symptoms of } \\
\text { Psychosexual } \\
\text { Dysfunctions } \\
\text { (Physical symptoms) } \\
\end{array}$ & Mean \pm SD & 宽 & 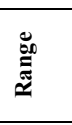 \\
\hline 1. Fatigue & $3.76 \pm 0.49$ & 4 & $1-4$ \\
\hline $\begin{array}{l}\text { 2. Doesn't like } \\
\text { talking about } \\
\text { sex before } \\
\text { intercourse }\end{array}$ & $3.35 \pm 0.74$ & 3 & $1-4$ \\
\hline $\begin{array}{l}\text { 3. Difficulty in } \\
\text { reaching } \\
\text { orgasm }\end{array}$ & $3.34 \pm 0.69$ & 3 & $1-4$ \\
\hline $\begin{array}{l}\text { 4. Difficulty in } \\
\text { keeping } \\
\text { erection }\end{array}$ & $3.32 \pm 0.78$ & 3 & $1-4$ \\
\hline $\begin{array}{l}\text { 5. Low sexual } \\
\text { desire }\end{array}$ & $3.31 \pm 0.72$ & 3 & $1-4$ \\
\hline $\begin{array}{l}\text { 6. Impaired } \\
\text { sexual arousal }\end{array}$ & $3.29 \pm 0.75$ & 3 & $1-4$ \\
\hline $\begin{array}{l}\text { 7. Inhibition } \\
\text { toward sex }\end{array}$ & $3.28 \pm 0.76$ & 3 & $1-4$ \\
\hline $\begin{array}{l}\text { 8. Difficulty in } \\
\text { beginning } \\
\text { erection }\end{array}$ & $3.14 \pm 0.66$ & 3 & $1-4$ \\
\hline
\end{tabular}

On the part of psychological symptoms, low self esteem during sexual intercourse, sexual dissatisfaction and feeling inhibited towards sex are the most common psychological symptoms expressed by the studied sample with mean of (3.45), (3.3) and (3.28) out of a possible score of (4) respectively while symptoms; loss of hope, anxiety and fear of sex, blaming self for sexual failure and depressed mood are moderately expressed by the studied sample with mean of (2.93), (2.84), (2.74) and (2.66) respectively. Suicidal ideation was the lowest prevalent psychological symptom with mean of (1.1) (Table, 5).

Table (5): Psychological symptoms of Psychosexual Dysfunctions of the studied sample $(n=100)$ :

\begin{tabular}{|c|c|c|c|}
\hline $\begin{array}{c}\text { Symptoms of } \\
\text { Psychosexual } \\
\text { Dysfunctions (Physical } \\
\text { symptoms) }\end{array}$ & $\begin{array}{c}\text { Mean } \pm \\
\text { SD }\end{array}$ & : & : \\
\hline $\begin{array}{ll}\text { 1. } & \begin{array}{l}\text { Psychosexual } \\
\text { discomfort }\end{array} \\
\end{array}$ & $3.81 \pm 4.12$ & 4 & $1-4$ \\
\hline $\begin{array}{ll}\text { 2. Low self-esteem during } \\
\text { sex }\end{array}$ & $3.45 \pm 0.74$ & 4 & $1-4$ \\
\hline 3. Sexual dissatisfaction & $3.3 \pm 0.93$ & 4 & $1-4$ \\
\hline $\begin{array}{ll}4 . & \text { Decrease sexual } \\
& \text { Fantasies } \\
\end{array}$ & $3.29 \pm 0.72$ & 3 & $1-4$ \\
\hline $\begin{array}{l}\text { 5. Doesn't express feeling } \\
\text { with wife }\end{array}$ & $2.99 \pm 0.92$ & 3 & $1-4$ \\
\hline 6. Loss of hope & $2.93 \pm 0.90$ & 3 & $1-4$ \\
\hline $\begin{array}{l}\text { 7. Anxiety, and fear of } \\
\text { sex }\end{array}$ & $2.84 \pm 0.92$ & 3 & $1-4$ \\
\hline $\begin{array}{l}\text { 8. } \begin{array}{l}\text { Blaming self for } \\
\text { sexual failure }\end{array} \\
\end{array}$ & $2.74 \pm 1.08$ & 3 & $1-4$ \\
\hline 9. Depressed Mood & $2.66 \pm 0.97$ & 3 & $1-4$ \\
\hline 10. Losing interest & $2.11 \pm 0.87$ & 2 & $1-4$ \\
\hline 11. Suicidal ideation & $1.1 \pm 0.33$ & 1 & $1-3$ \\
\hline
\end{tabular}

\section{Discussion:}

Several definitions have been proposed for sexual dysfunction according to its different causes (endocrinological, urological, psychological and neurological). Psychosexual dysfunctions are "all disturbances of one or more stages of the sexual response caused by psychological factors rather than physical factors that results in a disturbance of the patient's sexual and psychological life" ${ }^{,[8]}$. The prevalence of sexual dysfunction among patients with CKD was first studied in 1973 when Levy conducted the first 
epidemiological survey of sexuality in patients with CKD as cited in $\mathrm{Al}$ Khallaf $^{[20]}$.

The current study documents that the vast majority of the study sample (94\%) complain of psychosexual dysfunctions while only $6 \%$ expressed good psychosexual functions (Table, 3). These findings are attributed to the high prevalence of psychosexual dysfunctions among hemodialysis male patients. Reasons given for this high prevalence of psychosexual dysfunctions were claimed to be due to increased stress, depression and anxiety, drugs, diet, anemia, insomnia, insufficient hemodialysis, uremia, and hormonal changes ${ }^{[24]}$. Successful dialysis improves most symptoms of CKD, yet many patients continue to experience many forms of sexual dysfunction during dialysis treatment.

This finding is closer to a study ${ }^{[21]}$ conducted in Morocco which reported that $81 \%$ of hemodialysis patients suffered from a decrease in sexual activity after the onset of hemodialysis treatment. Additionally, Doss \& Polaschek[22] found that $78 \%$ of patient in New Zeal reported some degree of sexual dysfunctions, despite being medically stable, and adequately dialyzed, having no significant anemia, and only mild inflammation. In other words, the incidence rate of sexual dysfunction reported to be $9 \%$ before the initiation of hemodialysis and increases to $60 \%-70 \%$ during hemodialysis treatment ${ }^{[9,23]}$.

The prevalence of psychosexual dysfunction of the current study result $(94 \%)$ is higher than the other studies because the current study doesn't focus on the physical functions solely, but evaluate both physical and psychological functions together in one questionnaire. In addition, most of studies that conducted on male hemodialysis patients focus on ED not on sexual dysfunction as a general.
On the part of physical functions, the current study shows that fatigue, difficulty in reaching orgasm, difficulty in keeping erection, low sexual desire, impaired sexual arousal and difficulty in beginning erection are the most common symptoms expressed by the studied sample (Table, 4).

These physical symptoms may be due to organic causes affected CKD patients such as decreased arterial blood flow, venous leakage due to shunts, altered penile smooth muscle function, hormonal disturbances, side effect of medications, and neurogenic dysfunction, or may be due to psychological factors such as depression, and anxiety ${ }^{[24]}$. These sexual dysfunctions can erode one's sense of selfesteem, and lead to emotional, and marital tension, so it has great impact on the psychological state of the patients who become more stressed and more anxious

This result is consistent with a recent study ${ }^{[25]}$ in Jamaica which reported that ED, desire disorder and orgasmic disorder were found respectively in $91.4 \%, 88.3 \%$, and $81.6 \%$ of male subjects indicating that the majority of male patients were dissatisfied with their performance at intercourse after progressing to CKD. In addition, several studies focused on the prevalence of ED among hemodialysis patients. In Egypt the prevalence of ED in hemodialysis patients is $(86 \%)[11]$. The similar prevalence of ED was observed internationally in $\operatorname{Iran}[26](87.5 \%)$, in Turkey[27] (82.9\%), in Serbia[28] (83\%), in Pakistan ${ }^{[29]}(86 \%)$, and in Brazil ${ }^{[30]}$ (86.4\%).

On the part of psychological symptoms expressed by the studies sample, the current study shows that there are many psychological symptoms expressed by the studies sample. Most of them expressed low self esteem during sexual intercourse, not satisfying with their sexual functions and feeling inhibited towards sex while symptoms; loss of hope, 
anxiety and fear of sex, blaming self for sexual failure and depressed mood are moderately expressed by the studied sample. Suicidal ideation was the lowest prevalent psychological symptom (Table,5).

Most probably, these psychological symptoms are more specific due to sexual dysfunctions not to other stressors of hemodialysis. Nonetheless, it is also noted that hemodialysis patients expressed psychological symptoms related to other stressors and complications of hemodialysis such as sleep abnormalities, fluid loss, job loss, the cost of treatment, lifestyle change, time wasted, symptomrelated suffering, and marital and family role disruption ${ }^{[31]}$. The presence of anxiety and depression could be explained by the fact that these patients tend to distort their appraisal of sexual problems due to negative expectations and feelings of hopelessness, helplessness, and low self esteem. Suicidal ideation was the lowest prevalent psychological symptom because Egyptian people have strong religious beliefs. Religious beliefs are protective factors of suicide risk among hemodialysis patients $^{[32]}$. All such of these psychological symptoms produce difficulties in maintaining adequate sexual relationships. Social withdrawal further impairs the ability to form, and maintain intimate relationships.

These results are consistent with Charnow[33] who stated that the strongest predictor of sexual dysfunctions were depressive symptoms. Sexual dysfunctions were 2.4 times more likely to occur in hemodialysis male patients with depressive symptoms than in those without these symptoms. Moreover, the rates of depression are $26 \%$ in sexual dysfunctional hemodialysis patients ${ }^{[34]}$. The rate of anxiety disorders (27\%) was somewhat higher than the expected rate $(18 \%)$ on the basis of the "The Structured Clinical Interview for DSM-IV"[35]. These rates indicate that sexual dysfunctions are strongly associated with psychological state of hemodialysis patients.

In other words, Čengić \& Resić ${ }^{[36]}$ in Bosnia and Herzegovina reported that the most psychological symptoms emphasized were: anhedonia (84.5\%), pessimism $(74.5 \%)$, low self-esteem $(64 \%)$, anxiety (63.5\%), indecisiveness (51.5\%), irritability (43\%), depressive mood $(41.5 \%)$, feeling unsuccessful $(35.5 \%)$, reduced concentration $(35 \%)$, selfcriticism $(22 \%)$, feeling of punishment $(19.5 \%)$, feelings of guilt $(18 \%)$, and suicidal ideation $(11 \%)$.

Regarding suicidal ideation, the risk of death rate from suicide was $0.24 \%$ per 1000 dialysis patients/years, and patients with CKD significantly have higher rates of suicide compared with the general population in the United States ${ }^{[37]}$. Another study reported that among 200 hemodialysis patients, $21.5 \%$ had suicidal ideation; $3.5 \%$ had planned a suicide attempt in prior months; and $3.5 \%$ had attempted suicide during their lifetime ${ }^{[38]}$.

\section{Conclusion:}

Psychosexual dysfunctions are sexual dysfunctions that caused by psychological factors rather than physical factors and lead to serious psychological problems. Psychosexual dysfunctions are very common among hemodialysis male patients and characterized by both physical symptoms such as fatigue, difficulty in keeping erection, and low sexual desire and psychological symptoms as low self esteem during sexual intercourse, sexual dissatisfaction, and anxiety, and fear of sex.

\section{Recommendation:}

The study recommends that, assessment of sexual dysfunctions and psychological state hemodialysis patients should be conducted by all health care providers. The psychiatric liaison nurse should be available on hemodialysis units. Psychiatric liaison nursing programs 
should be planned in hemodialysis units to educate nursing staff about how to manage psychosexual dysfunctions.

Limitations:

Some patients refused to participate in the study. They avoid talking about their psychosexual dysfunctions because of feelings of shame or because of their several failed tries to manage it.

Acknowledgements:

We would like to thank all the patients who participated in the study and dialysis staff of Urology and Nephrology Center for their help and cooperation during the study period and appreciate the great efforts of the supervisors in this work.

References:

1. Kamal NN, Kamel EG, Eldessouki KH, Ahmed MG. Health-related quality of life among hemodialysis patients at El-Minia University Hospital, Egypt. J Public Health. 2013;21 (2) $): 193-200$.

2. Ahmed A, Allam M, Habil E, Metwally A, Ibrahiem N, Radwan M, et al. Development of practice guidelines for hemodialysis in Egypt. Indian J Nephrol. 2010;20(4):193202.

3. Palmer BF. Sexual dysfunction in men and women with chronic kidney disease and end-stage kidney disease. Adv Ren Replace Ther. 2003; 10(1):48-60.

4. Finkelstein FO, Shirani S, Wuerth D, Finkelstein SH. Therapy Insight: Sexual dysfunction in patients with chronic kidney disease. Nat Clin Pract Nephrol. 2007;3:200-207.

5. Ayub W, Fletcher S. End stage renal disease and erectile dysfunction. Is there any hope? Nephrol Dial Transplant. 2000:15:1525-1528.

6. Laumann EO, Nicolosi A, Glasser DB, Paik A, Gingell C, Moreira E. Sexual problems among women and men aged 40-80 Y: Prevalence and correlates identified in the global study of sexual attitudes and behaviors, Int J Impot Res. 2005; 17:39-57.

7. WordWeb Online [Internet]. Physical condition; 2013 [cited 2013 December 1]. Available from: http://wordwebonline.com

8. Safer DA. [Internet]. Psychosexual dysfunction (sexual aversion; sexual apathy; hypoactive sexual desire); 2012 [cited 2013 December 25]. Available from: http://psych.med.nyu.edu

9. Soykan A, Boztas H, Kutlay S, Ince E, Nergizoglu G, Dileko“z AY, et al. Do sexual dysfunctions get better during dialysis? Results of a sixmonth prospective follow-up study from turkey. Int J Impot Res. 2005; 17:359-363.

10. Black K. Sexual function and end stage renal failure, educational supplement. Ren Soc of Aust J. 2008;5(1):27-30.

11. Ali M, Abdel-Hafez H, Mahran A, Mohamed A, Mohamed H, El-Shazly $A$, et al. Erectile dysfunction in chronic renal failure patients undergoing hemodialysis in Egypt. Int J Impot Res. 2005; 17(2): 180-185.

12. Navaneethan SD, Vecchio M, Chem P, Johnson DW, Saglimbene V, Graziano G, et al. Prevalence and correlates of self-reported sexual dysfunction in CKD: A Metaanalysis of observational studies. Am J Kidney Dis. 2010;56(4):670-685.

13. Gerogianni GK, Babatsikou FP. Identification of Stress in Chronic Haemodialysis. Health Science Journal. 2013; 7 (2): 169-176.

14. Ayaz S. Sexuality and nursing process: A Literature review. Sex Disabil. 2013;31:3-12.

15. Parsonage M, Fossey M, Tutty C. Liaison psychiatry in the modern NHS centre for mental health 
PREVALENCE OF PSYCHOSEXUAL DYSFUNCTIONS AMONG etc...

[Internet]; 2012 [cited 2013 October

12]. Available from:

http://www.centreformentalhealth.org. $\underline{\mathrm{uk}}$

16. Leentjens AFG, Rundell JR, Wolcott DL, Guthrie E, Kathol R, Diefenbacher A. Psychosomatic medicine and consultation-liaison psychiatry: Scope of practice, processes, and competencies for psychiatrists working in the field of CL psychiatry or psychosomatics. J Psychosom Res. 2011;70:486-491.

17. Barsoum R. End-stage renal disease in the developing world. J Artif Organs. 2002;26:735-6.

18. McGahuey CA, Gelenberg AJ, Laukes CA, Moreno FA, Pedro L, Delgado PL., et al. The Arizona Sexual Experience Scale (ASEX): Reliability and validity. J Sex Marital Ther. 2000;26:25-40.

19. Infrasca R. Sexual Dysfunction Questionnaire: Scale development and psychometric validation. Giom Ital di Psicopatol. 2011;17:523-260.

20. Al Khallaf HH. Analysis of sexual functions in male nondiabetic hemodialysis patients and renal transplant recipients. Transpl Int. 2010;23:176-181.

21. Zamd M, Gharbi MB, Ramdani B, Zaïd D. Sexual dysfunction in male patients undergoing hemodialysis in Morocco. Saudi J Kidney Dis Transpl. 2005; 16(1): 33-39.

22. Doss F, Polaschek N. Assessing sexual dysfunction in people living on dialysis in a New Zealand Renal Service. Ren Soc Aust J. 2012;8(3):104-110.

23. Özdemir C, Eryılmaz M, Yurtman F, Karaman T. Sexual functioning after renal transplantation. Transplant Proc. 2007;39:14511454.

24. Rathi M, Ramachandran R. Sexual and gonadal dysfunction in chronic kidney disease: Pathophysiology. Indian J Endocrinol Metab. 2012;16(2):214-219.

25. Hoe KK, Soyibo AK, James K, Barton EN. The prevalence of sexual dysfunction among patients with end stage renal disease in Jamaica. West Indian Med J. 2013;62(9):234-247.

26. Mehrsai A, Mousavi S, Nikoobakht M, Khanlarpoor T, Shekarpour L, Pourmand G. Improvement of erectile dysfunction after kidney transplantation: The role of the associated factors. Urol J. 2006;3(4):240-244.

27. Inci k, Hazirolan T, Ati FT, Oruc O, Tombul T, Tasar C, et al. Coronary artery calcification in $\mathrm{HD}$ patients and their correlation with the prevalence of ED. Transplant Proc. 2008;40(1):77-80.

28. Stolic RV, Bukumiric ZM, Jovanovic AN, Peric VM, Sovtic SR, Belic PB, et al. Residual renal function and erectile dysfunction in patients on hemodialysis. Int Urol Nephrol. 2012;44:891-895.

29. Mumtaz A, Anees M, Barki MB, Sami W, Hussain S, Nazir M. Erectile dysfunction in haemodialysis patients. J Ayub Med Coll Abbottabad. 2009;21(2):4-7.

30. Neto AF, Rodrigues MA, Fittipaldi JA, Moreira ED. The epidemiology of erectile dysfunction and its correlates in men with chronic renal failure on hemodialysis in Londrina, Southern Brazil. Int J Impot Res. 2002;14(2):19-26.

31. Al Nazly E, Ahmad M, Musil C, Nabolsi M. Hemodialysis stressors and coping strategies among Jordanian patients on hemodialysis: A Qualitative study. Nephrol Nurs J. 2013;40(4):321-327.

32. Martiny C, De Oliveira SAC, Neto JP, Nardi AE. Factors Associated with Risk of Suicide in Patients with 
Hemodialysis. Compr Psychiatry. 2011;52:465-468.

33. Charnow JA. Erectile dysfunction highly prevalent among men on hemodialysis [Internet]; 2014 [cited 2014 July 1]. Available from: http://www.renalandurologynews.com

34. Watnick S, Wang PL, Demadura T, Ganzini L.. Validation of two depression screening tools in dialysis patients. Am J Kidney Dis. 2005;46:919-924.

35. Kimmel PL, Peterson RA, Weihs KL, Simmens SJ, Boyle DH. Psychologic functioning, quality of life and behavioral compliance in patients beginning hemodialysis. J Am Soc Nephrol. 1996; 7:2152-2159.

36. Čengić B, Resić $H$. Depression in hemodialysis patients. Bosn J Basic Med Sci. 2010;10(1):74-78.

37. Kurella M, Kimmel PL, Young BS, Chertow GM. Suicide in the United States end-stage renal disease program. J Am Soc Nephrol. 2005;16:774-781.

38. Chen CK, Tsai YC, Hsu HJ, Wu IW, Sun CY, Chou CC. Depression and suicide risk in hemodialysis patients with chronic renal failure. Psychosomatics. 2010;51:528-528. 